nhân viên y tế trong các sự cố y khoa Howell cho rằng chỉ $5 \%$ là nguyên nhân đến từ người bệnh. Nguyên nhân môi trường chúng tôi nghiên cứu thấy nhóm này chiếm tỳ lê $4,9 \%$ nguyên nhân gây ra sự cố và xếp hàng thứ 5 , trong khi đó tác giả Nguyễn Thị Thu Hà là $9,7 \%$ và xếp hàng thứ 3 [2]. Tác giả Gao $X$ thì cho rằng điêu này tùy thuộc vào môi trường của từng bệnh viện [7]. Nhóm nguyên nhân khác chúng tôi có kết quả chiếm tỷ lệ $12,9 \%$, tác giả Nguyền Thị Thu Hà là 4,8\%, Lương Ngọc Khuê, Phạm Đức Mục chưa đưa ra nhận định này. Trong nghiên cứu của chúng tôi còn nhận định thấy có $8,2 \%$ sự cố được báo cáo không phân tích được nguyên nhân, việc này cũng đúng với nhận định của các tác giả Lương Ngọc Khuê, Phạm Đức Mục về sự phức tạp trong nguyên nhân gây ra sự cố sẽ ngày càng nhiều và sẽ cần được bổ sung trong các văn bản hướng dẫn về vấn đề này [2],[3],[4].

\section{KẾT LUẬN}

Đặc điểm của các sự cố y khoa được báo cáo tại bệnh viện đa khoa tỉnh Phú Thọ rất đa dạng với 365 sự cố y khoa được nhân viên y tế của bệnh viện báo cáo ghi nhận và phân tích: $56.7 \%$ xảy ra tại nhóm chuyên môn khối Nội, 36.2\% sự cố xảy ra tại buồng điều trị, $8.5 \%$ sự cố xảy ra vào ngày Thứ Sáu hàng tuần, $21.6 \%$ sự cố xảy ra trong ngày vào thời gian từ $12-18 \mathrm{~h}, 61.1 \%$ đối tượng xảy ra sự cố là người bệnh, $62.7 \%$ sự cố được báo cáo gẩy ra mức độ tổn thương nhẹ, $58.4 \%$ sự cố xảy ra làm tăng nguồn lực phục vụ cho người bệnh, $60.8 \%$ nguyên nhân gây ra sự cố do nhóm nhân viên y tế.

\section{TÀI LIẸU THAM KHẢO}

1. Dương Minh Đức (2018), "Báo cáo sự cố y khoa và một số yếu tố ảnh hưởng tại Bệnh viện Hữu Nghị Việt Đức năm 2018", Luận vằn thạc sỹ.

2. Nguyễn Thị Thu Hà (2019), "Thực trạng báo cáo sự cố y khoa và một số yếu tố ảnh hưởng tại bệnh viện Việt Nam - Thụy Điển Uông Bí giai đoạn 2013-2019". Luận văn thạc sỹ quản lý bệnh viện.

3. Lương Ngọc Khuê (2014), "Tài liệu đào tạo liên tưc an toàn người bênh", Nhà xuất bản $Y$ học.

4. Phạm Đức Mục (2012), "Giảm thiểu sự cố y khoa trong các bệnh viện", Hội điều dưỡng Việt Nam. Website của Bộ y tế Việt Nam.

5. Nguyễn Thị Thu (2017), "Nghiên cứu thực trang báo cáo sự cố y khoa và một số yếu tố ảnh hưởng tại các khoa lâm sàng tại bệnh viện Phụ Sản Hă Nội", Luận văn thạc sỹ.

6. Lể Thanh Tùng (2019), "Thực trạng báo cáo sự cố y khoa và môt số yêu tố ánh hưởng tai Bênh viện Hữu nghị Việt Nam - Cu Ba Đồng Hới", Luận văn thạc sỹ.

7. X. Gao et al (2019), "Implications from China patient safety incidents reporting system", Ther Clin Risk Manag. 15, tr. 259-267.

8. T. Shimizu, Y. Tokuda (2012), "Pivot and cluster strategy: a preventive measure against diagnostic errors", Int J Gen Med. 5, tr. 917-21.

\title{
MộT Số YẾU Tố LIÊN QUAN ĐẾN THỰC HÀNH PHÒNG BÊNH VIÊM GAN B NGHỀ NGHIÊPP CỦA ĐIỂU DƯỚNG LÂM SÀNG BÊ̂NH VIỆN TỈNH BẾN TRE, 2018
}

\author{
Nguyễn Ngọc Bích ${ }^{1}$, Nguyễn Thị Mỹ Khánh², Nguyễn Thu Hà ${ }^{3}$
}

\section{TÓM TẮT}

Viêm gan $B$ nghề nghiệp là một bệnh tiềm ẩn nguy cơ đe doạ sức khoẻ nhân viên y tế, đặc biệt là điêu dưỡng do thường xuyên tiếp xúc với máu, dịch của người bệnh nhiễm vi rút viêm gan $B$. Nghiên cứu tìm hiểu một số yếu tố liên quan đến thực hành phòng bệnh viêm gan $B$ nghề nghiệp của điều dưỡng lâm sàng tại Bệnh viện Nguyễn Đình Chiểu Bến Tre. Nghiên cứu mô tả cắt ngang có phân tích, kết hợp

\footnotetext{
${ }^{1}$ Trường Đại học Y tế công cộng

²Bênhh viện Nguyễn Đinh Chiểu Bến Tre

3 Viện Sức khoẻ nghề nghiệp và Môi trường

Chịu trách nhiệm chính: Nguyễn Ngọc Bích

Email: nnb@huph.edu.vn

Ngày nhận bài: 9.3.2021

Ngày phản biện khoa học: 10.5.2021

Ngày duyệt bài: 18.5.2021
}

đinh tính đã được thực hiên từ tháng 4 năm 2018 đến tháng 8 năm 2018, qua phát vấn 420 điều dưỡng tại Bênh viện Nguyễn Đình Chiểu. Đồng thời, có 03 cuộc phỏng vấn sâu lãnh đạo bệnh viện, lãnh đạo Phòng Điều dưỡng, lãnh đao Khoa Kiểm soát nhiê̂m khuẩn và 01 cuộc thảo luận nhóm cũng đã được tiến hành. Kết quả nghiên cứu cho thây $89,5 \%$ điêu dưỡng có thực hành đúng từ $2 / 3$ tiêu chí trong dự phòng phơi nhiếm viêm gan $B$ nghề nghiệp. Nhóm điêu dưỡng có kiến thức về bệnh viêm gan $B$ nghề nghiệpkhông đạt có thực hành phòng bệnh viêm gan $B$ nghể nghiệp không đúng gấp 2,3 lần so với nhóm có kiến thức đạt ( $\mathrm{p}=$ $0,007)$. Nhóm điều dưỡng có kiến thức phòng bệnh viêm gan $B$ nghề nghiệpkhông đạt có thực hành phòng bệnh viêm gan $B$ nghề nghiệp không đúng gấp 4,3 lần so với nhóm có kiến thức đạt $(p<0,0001)$. Nghiên cứu khuyến nghị tăng cường kiến thức về bệnh cũng như kiến thức về cách phòng bệnh viêm gan $B$ nghề nghiệp cho điều dưỡng lâm sàng tại bệnh viện, tăng cường kiểm tra, giám sát việc thực hiện các 
quy trình kỹ thuật trong chăm sóc người bệnh, đảm bảo tốt các nguyên tắc trong phòng ngừa chuẩn và nhiễm khuẩn bệnh viện.

Tư khoá: viêm gan $B$, bệnh nghề nghiệp, yếu tố liên quan, điều dưỡng, bệnh viện

\section{SUMMARY}

FACTORS RELATED TO PRACTICE TOWARD OCCUPATIONAL HEPATITIS B

PREVENTIONOF CLINICAL NURSES IN

NGUYEN DINH CHIEU HOSPITAL, 2018

Occupational hepatitis $B$ is one of the most common occupational risks for health workers, especially nurses as they regularly exposed to blood and other contaminants from patients. This study aimed to investigate factors related to prevention practice among clinical nurses at Nguyen Dinh Chieu, Ben Tre. The cross sectional study using quantitative and qualitative methods was implemented from April to August 2018. 420 nurses completed self administered questionnaire. 3 indept interviews and one focus group discussion was also conducted. Results show that $89.5 \%$ of nurses had adequate practices on prevention of occupational hepatitis $B$. Nurses with inadequate knowledge about the disease were 2.3 more likely practice inadequately compared to the others. Nurses with inadequate knowledge on prevention were 2.3 more likely practice inadequately compared to the others. The differences were statistically significant. It was recommended that the hospital board should strengthen knowledge on hepatitis $B$ as well as on how to prevent the disease. Supervision should also be implemented.

Keywords: Hepatitis B, occupational disease, factor, nurse, hospital

\section{I. ĐẶT VẤN ĐỀ}

Viêm gan vi rút là một nhóm bệnh truyền nhiễm rất phổ biến và nguy hiểm. Trong đó, viêm gan $B$ (VGB) đã và đang là vấn đề y tế nghiêm trọng có tính chất toàn câu. Bệnh nghiêm trọng vì ngoài tính chất lây nhiễm cao trong cộng đồng, bệnh còn để lại những biến chứng và hậu quả nặng nề (1)

Viêm gan vi rút $B$ là một trong những bênh được công nhận là bệnh nghề nghiệp được bảo hiểmở Việt Nam (2)Điều dưỡng (ĐD) bệnh viện khi tiếp xúc với người bệnh (NB) có nguy cở bị tổn thương do vật sắc nhọn hay văng dính máu, dịch. Các yếu tố nguy cơ có thể gây tổn thương da trong bệnh viện như: Kim tiêm dưới da, mảnh thủy tinh, mũi khâu, kim bướm, mũi khoan,... (3)

Theo Tổ chức $Y$ tế Thế giới, có tới $50 \%$ các mũi tiêm ở các nước đang phát triển là không an toàn. Các tác nhân gây bệnh qua đường máu cũng góp phân gây bệnh ở nhân viên y tế (NVYT). Ước tính 39\% ca nhiễm HBV là do tai nạn nghề nghiệp (TNNN) $(4,5)$. Trong các số NVYT không được điều trị dự phòng sau phơi nhiễm, nguy cơ nhiễm khuẩn sau khi bị tổn thương do kim tiêm là 23\%-62\% đối với HBV $(6,7)$. Tỷ lệ NVYT nhiễm HBV mạn tính trong nghiên cứu tại miền Bắc của Khúc Xuyền là $13,1 \%$ (8) nghiên cứu của Nguyễn Quang Tâp tại Hải Phòng là 14,8\% (9), miên Trung của Viên Chinh Chiến là 17,6\%, ở miền Nam tại Bệnh viện Nhân dân Gia Định là 39\%. Tỷ lệ nhiểm cao nhất ở nhóm y tá/ĐD là $61,9 \%$, bác sĩ 17,5\%, hộ lý và y công chiếm 9,5\%.

Nghiên cứu được thực hiện nhằm tìm hiểu thực trạng thực hành phòng bệnh VGBNN của ĐD tại các khoa lâm sàng trong bệnh viện và một số yếu tố liên quan.

\section{II. ĐỐI TƯỢNG VÀ PHƯƠNG PHÁP NGHIÊN CỨU}

\section{1. Đối tượng nghiên cứu:}

- Điều dưỡng viên hiên đang công tác tại các khoa lâm sàng Bệnh viện Nguyễn Đình Chiểu Bến Tre.

- Lãnh đạo bệnh viện, lãnh đạo phòng Điều dương, Lãnh đạo khoa Kiểm soát nhiểm khuẩn.

2.2. Thời gian và địa điểm nghiên cứu:

- Thời gian: Từ tháng 04/2018 đến tháng 08/2018.

- Địa điểm: Bệnh viện Nguyễn Đình Chiểu, Thành phố Bến Tre, tỉnh Bến Tre.

\subsection{Phương pháp nghiên cứu:}

- Thiết kế nghiên cứu: Nghiên cứumô tả cắt ngang có phân tích, kết hợp định lượng và định tính.

2.4. Mẫu và phương pháp chọn mẫu:

2.4.1. Cõ mấu cho nghiên cứu định lượng: Lây mẫu toàn bộ, toàn bộ điêu dưỡng các khoa lâm sàng Bênh viện Nguyễn Đình Chiểu đủ tiêu chuẩn lựa chọn và đồng ý tham gia nghiên cứu. Thực tế đối tượng nghiên cứu là 420 người.

2.4.2. Cỡ mâuu cho nghiên cứu định tính:

Chọn mẫu có chủ đích các đối tượng phỏng vấn sâu. Đó là những người quản lý bệnh viện, quản lý điêu dưỡng và quản lý công tác kiểm soát nhiễm khuẩn của bệnh viện.

Số lượng các cuộc phỏng vấn sâu trong nghiên cứu được thực hiện như sau:

Phỏng vấn sâu 01 lãnh đạo bệnh viện.

Phỏng vấn sâu 01 lãnh đạo phòng Điều dưỡng.

Phỏng vấn sâu 01 lãnh đạo khoa Kiểm soát nhiễm khuẩn.

Dựa vào kết quả thu được từ nghiên cứu định lượng, đã chọn ra 10 điêu dưỡng có số điểm kiến thứcchung về VGBNN thấp nhất, đảm bảo cân đối về cơ cấu tuổi, trình độ chuyên môn và thâm niên công tác tại bệnh viện.

2.5. Phương pháp thu thập số liệu:

2.5.1. Công cụ thu thập số liệu định 
lượng. Sử dụng bộ câu hỏi tự điền được thiết kế sẵn, phát vấn cho các điều dưỡng làm việc tại các khoa lâm sàng

\section{Đánh giá thực hành:}

Nghiên cứu tiến hành đánh giá chung về thực hành dự phòng phơi nhiễm và xử trí khi bị TNNN.

*Đánh giá dự phòng phơi nhiễm với các yễu tố nguy cơ (chung cho tất cả các ĐTNC)

- Phần thực hành có các câu hỏi từ C42 đến C53. Mỗi câu tương ứng với một số điểm nhất định, dựa vào phần trả lời của ĐTNC, theo thang điểm để tính điểm và đánh giá đúng hay không đúng.

- Điểm tối đa cho phần đánh giá thực hành là 12 điểm. Nếu ĐTNC thực hành đúng trên $2 / 3$ các tiêu chí thì được coi là thực hành đúng, điểm đúng $>9$ điểm, không đúng $<9$ điểm.

* Đánh giá thực hành xử trí khi bị TNNN:

- Phần thực hành xử trí khi bị tai nạn do vật sắc nhọn. Mỗi câu hỏi tương ứng với một số điểm nhất định. Điểm tối đa cho phần đánh giá thực hành là 5 điểm. Thực hành đúng $>4$ điểm, không đúng $<4$ điểm.

- Phần thực hành xử trí khi bị văng bắn, dính máu dịch. Mỗi câu hỏi tương ứng với một số điểm nhất định. Điểm tối đa cho phần đánh giá thực hành là 2 điểm. Thực hành đúng: 2 điểm, không đúng <2 điểm.

- Đánh giá thực hành xử trí chung đúng khi bị tai nạn nghề nghiệp: Xử trí đúng khi bị tai nạn do vật sắc nhọn hoặc khi bị văng bắn máu dịch hoặc xử trí đúng cả hai tai nạn khi bị cả hai tai nạn nghề nghiệp (do vật sắc nhọn và dính/văng bẳn máu, dịch).

2.5.2. Công cư thu thập chủ đề định tính. Nghiên cứu viên xây dựng bộ câu hỏi theo chủ đề nghiên cứu gồm:

- 03 hướng dẫn phỏng vấn sâu: 01 lãnh đạo bệnh viện, 01 lãnh đạo phòng Điều dưỡng, 01 trưởng khoa Kiểm soát nhiễm khuẩn

- 01 hướng dẫn thảo luận nhóm (10 ĐD của 10 khoa lâm sàng) được chọn chủ đích

\subsection{Các biến số nghiên cứu}

2.6.1. Biến số nghiên cứu định lượng

- Nhóm biến số mô tả thực hành:

+ Nhóm thực hành dự phòng phơi nhiễm

+ Nhóm thực hành xử trí khi bị tai nạn nghề nghiệp.

- Nhóm biến số về yếu tố cá nhân của đối tượng nghiên cứu: Tuổi, giới tính, thâm niên công tác, trình độ chuyên môn.

- Kiến thức với thực hành phòng bệnh VGBNN.

\subsubsection{Các chủ đề nghiên cứu định tính:}

\begin{tabular}{|c|c|c|}
\hline STT & Chủ đề nghiên cứu & Đôii tượng \\
\hline \multicolumn{3}{|c|}{ Các yếu tố liên quan đến kiến thức, thực hành phòng bệnh viêm gan B nghề nghiệp } \\
\hline 1 & Đánh giá việc cung cấp phương tiện bảo hộ lao động cho nhân & Lãnh đạo bệnh viện, lãnh \\
\hline 2 & $\begin{array}{l}\text { Đánh giá việc tập huấn- đào tạo kiến thức về phòng bệnh viêm } \\
\text { gan B nghề nghiệp }\end{array}$ & $\begin{array}{l}\text { lãnh đạo khoa Kiểm soát } \\
\text { nhiếm khuẩn và điều }\end{array}$ \\
\hline 3 & Đánh giá việc kiểm tra, giám sát các hoạt động phòng phơi nhiểm & dưỡng viên ở các khoa \\
\hline
\end{tabular}

\subsection{Phương pháp phân tích số liệu}

\subsubsection{Số liệu định lượng}

- Quản lý số liệu: Sau khi thu thập, phiếu điều tra được kiểm tra đây đủ trước khi NCV tiến hành làm sạch, mã hóa và nhập số liệu bằng phần mềm EpiData 3.1. Xử lý số liệu bằng phần mềm SPSS 18.0.

- Phân tích số liệu: Kết quả phân tích được chia làm 2 phần:

+ Phần miêu tả những bảng, biểu thể hiện tần số của các biến nghiên cứu.

+ Phần phân tích: Sử dụng kiểm định Khi bình phương, tỷ suất chênh (OR) để xác định các yếu tố liên quan đến kiến thức, thực hành phòng bệnh VGBNNcủa ĐD lâm sàng.

2.7.2.Số liệu định tính. Số liệu định tính sau khi thu thập dưới dạng những ghi chép trong sổ sách và băng ghi âm. Tiến hành gõ băng phỏng vấn, mã hóa bảng gõ băng, phân tích, tổng hợp theo chủ đề. NCV lựa chọn các câu trích dẫn phù hợp với các chủ đề để tìm ra những thông tin trả lời cho các câu hỏi chính trong nghiên cứu và từ đó làm sáng tỏ mục tiêu nghiên cứu.

2.8. Đạo đức nghiên cứu. Tuân thủ quy trình xét duyệt của Hội đồng Đạo đức - Trường Đại học Y tế Công cộng, được Hội đồng đạo đức trong nghiên cứu y sinh hoc Trường Đai học $Y$ tế công cộng thông qua trước khi tiến hành triển khai tại bệnh viện (Quyết định số 301/2018/ YTCC-HD3 ngày 26 tháng 4 năm 2018 về việc chấp thuận các vấn đề đạo đức y sinh học).
III. KẾT QUẢ NGHIÊN CứU
Bảng 3. 1.Đăc điểmcá nhân của đôi tượng nghiên cứu $(N=420)$ 


\begin{tabular}{|c|c|c|}
\hline Sau đại học & 0 & 0 \\
\hline Đại học & 78 & 18,6 \\
\hline Cao đằng & 64 & 15,2 \\
\hline Trung học & 278 & 66,2 \\
\hline \multicolumn{3}{|c|}{ Thâm niên công tác } \\
\hline$<5$ năm & 144 & 34,3 \\
\hline 6-10 năm & 129 & 30,7 \\
\hline$>11$ năm & 147 & 35,0 \\
\hline \multicolumn{3}{|c|}{ Công việc đang làm } \\
\hline Tiêm, truyền & 359 & 85,5 \\
\hline $\begin{array}{l}\text { Lấy bệnh phấm } \\
\text { (máu, dịch) }\end{array}$ & 329 & 78,3 \\
\hline Cho NB uống thuốc & 327 & 77,9 \\
\hline Làm thủ thuật & 364 & 86,7 \\
\hline Cọ rửa dụng cụ & 299 & 71,2 \\
\hline Xét nghiệm & 121 & 28,8 \\
\hline Khác & 51 & 12,1 \\
\hline \multicolumn{3}{|c|}{$\begin{array}{c}\text { Biết về nguy cơ phơi nhiếm và mắc bệnh } \\
\text { VGB của NVYT }\end{array}$} \\
\hline Đã biết & 404 & 96,2 \\
\hline Chưa biết & 16 & 3,8 \\
\hline \multicolumn{3}{|c|}{ Xét nghiệm HBsAg } \\
\hline Có xét nghiệm & 417 & 99,3 \\
\hline Chưa xét nghiệm & 3 & 0,7 \\
\hline \multicolumn{3}{|c|}{ Lịch sữ tiềm ngừa văc xín VGB } \\
\hline Đã tiêm ngừa đủ & 281 & 66,9 \\
\hline Chưa tiêm ngừa đủ & 139 & 33,1 \\
\hline
\end{tabular}

Gân 2/3 ĐD có trình độ chuyên môn là trung học, tỷ lệ $66,2 \%$, còn lại là cao đẳng và đại học chiếm tỷ lệ 33,8\%, không có ĐD trình độ sau đại học làm cống tác lâm sàng.

ĐD có thâm niên công tác trong ngành y tế $<5$ năm là 34,3\%, từ 6 năm trở lên chiếm $65,7 \%$. Thâm niên thấp nhất là 1 năm và cao nhất là 40 năm, thâm niên trung bình là $10 \pm 7,8$ năm.

Công việc được thực hiện trong quá trình làm việc có ảnh hưởng đến mức độ phơi nhiễm với yếu tố gây bệnh. Trên 70\% ĐD phải thường xuyên thực hiện các công việc tiếp xúc với vật sắc nhọn hay máu, dịch của NB.
Có 99,3\% ĐD đã được xét nghiêm HbsAg và có $66,9 \%$ ĐD đã tiêm đủ 3 mũi vắc xin VGB.

Bảng 3.2. Thức hành phòng bệnh viêm gan B nghề nghiệp ( $N=420)$

\begin{tabular}{|c|c|c|}
\hline $\begin{array}{c}\text { Thực hành phòng } \\
\text { bệnh VGBNN }\end{array}$ & Tân số & $\begin{array}{c}\text { Tỷ lệ } \\
(\mathbf{\%})\end{array}$ \\
\hline Đúng & 376 & 89,5 \\
\hline Không đúng & 44 & 10,5 \\
\hline Tống & $\mathbf{4 2 0}$ & $\mathbf{1 0 0}$ \\
\hline
\end{tabular}

Kết quả đánh giá thực hành dự phòng bệnh VGBNN trong quá trình làm việc đa sốĐD thực hiện tốt các biện pháp dự phòng $(89,5 \%)$, tuy nhiên vẫn còn $10,5 \%$ ĐD thực hành không đúng.

Thức hành xử trí khi bị tai nạn nghề nghiệp:

Bảng 3.3. ĐD bị tổn thương do vật sắc nhọn 6 tháng gân đây $(N=420)$

\begin{tabular}{|c|c|c|c|c|}
\hline \multirow{3}{*}{$\begin{array}{c}\text { Tai nạn nghề } \\
\text { nghiệp }\end{array}$} & \multicolumn{4}{|c|}{ Thưc hành } \\
\hline & \multicolumn{2}{|c|}{ Có } & \multicolumn{2}{|c|}{ Không } \\
\hline & $\mathbf{n}$ & $\%$ & n & $\%$ \\
\hline $\begin{array}{l}\text { Tốn thương do vật } \\
\text { sắc nhọn }\end{array}$ & 28 & 6,7 & 392 & 93,3 \\
\hline $\begin{array}{l}\text { Do dính/ văng bắn } \\
\text { máu, dịch }\end{array}$ & 53 & 12,6 & 367 & 87,4 \\
\hline
\end{tabular}

Trong 6 tháng trước thời điếm nghiên cứu, ĐD bị tổn thương do vật sắc nhọn là $28(6,7 \%)$, do dính/văng bắn máu,dịch của NB là 53 (12,6\%) với tổng số 67 điều dưỡng bi ít nhất một loại tổn thương

Bàng 3.4. Thức hành xư trí của ĐD khi bi TNNN ( $n=67)$

\begin{tabular}{|c|c|c|}
\hline $\begin{array}{c}\text { Thực hành xử trí của ĐD } \\
\text { khi bị TNNN }\end{array}$ & $\begin{array}{c}\text { Tân } \\
\text { số }\end{array}$ & $\begin{array}{c}\text { Tỷ lệ } \\
(\mathbf{\%})\end{array}$ \\
\hline Đúng & 43 & 64,2 \\
\hline Không đúng & 24 & 35,8 \\
\hline
\end{tabular}

Kết quả đánh giá thực hành xử trí TNNN của 67 ĐD (là những người bi ít nhất một TNNN: Bị tai nạn do vật sắc nhọn hoặc dính/ văng, bắn máu, dịch của NB hay bị cả hai tai nạn trên), tỷ lệ ĐD xử trí đúng là $64,2 \%$ và $35,8 \%$ ĐD xứ trí không đúng.

Bảng 3.5. Môi liên quan giữa nhóm tuổi và thực hành phòng bệnh VGBNN (N = 420)

\begin{tabular}{|c|c|c|c|c|c|c|c|}
\hline \multirow{3}{*}{\multicolumn{2}{|c|}{ Biến độc lập }} & \multicolumn{4}{|c|}{ Thực hành phòng bệnh VGBNN } & \multirow{3}{*}{$\begin{array}{c}\text { OR } \\
\text { (CI 95\%) }\end{array}$} & \multirow{3}{*}{$\mathbf{p}$} \\
\hline & & \multicolumn{2}{|c|}{ Không đúng } & \multicolumn{2}{|c|}{ Đúng } & & \\
\hline & & $\mathbf{n}$ & $\%$ & $\mathbf{n}$ & $\%$ & & \\
\hline \multirow{2}{*}{ Nhóm tuổi } & $20-29$ & 24 & 12,4 & 169 & 87,6 & \multirow{2}{*}{$\begin{array}{c}1,5 \\
(0,8-2,7)\end{array}$} & \multirow{2}{*}{0,14} \\
\hline & $>30$ & 20 & 8,8 & 207 & 91,2 & & \\
\hline
\end{tabular}

Không tìm thấy mối liên quan giữa nhóm tuối và thực hành phòng bênh VGB có ý nghĩa thống kê với $p=0,14$. Tỷ lệ thực hành phòng bệnh VGBNN ở nhóm tuổi 20-29 khồng đạt gấp1,5 lần so với ĐD ở nhóm tuổi > 30 .

Bảng 3.6. Môi liên quan giữa giới tính và thực hành phòng bệnh VGBNN (N = 420)

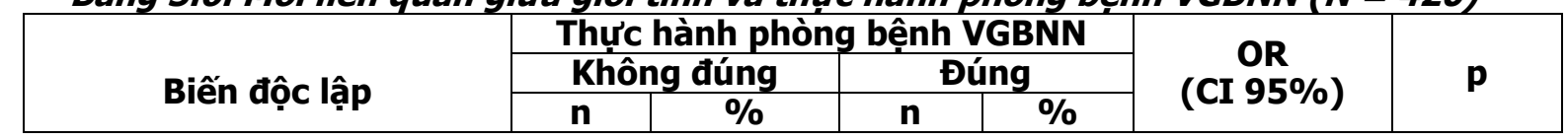




\begin{tabular}{|c|c|c|c|c|c|c|c|}
\hline \multirow{2}{*}{ Giới tính } & Nam & 11 & 12,8 & 75 & 87,2 & 1,3 & \multirow{2}{*}{0,27} \\
\cline { 2 - 6 } & Nữ & 33 & 9,9 & 301 & 90,1 & $(0,6-2,8)$ & \\
\hline
\end{tabular}

Không có mối liên quan có ý nghĩa thống kê giữa giới tính với thực hành phòng bệnh VGBNN với $p$ $=0,27$. Nhóm ĐDnam thực hành phòng bệnh VGBNN không đúnggấp1,3 lân so với nhóm ĐDnữ.

Bảng 3. 7. Mối liên quan gi̛ưa thâm niên công tác và thực hành phòng bệnh VGBNN (N = 420)

\begin{tabular}{|c|c|c|c|c|c|c|c|}
\hline \multirow{3}{*}{\multicolumn{2}{|c|}{ Biến độc lập }} & \multicolumn{4}{|c|}{ Thực hành phòng bệnh VGBNN } & \multirow{3}{*}{$\begin{array}{c}\text { OR } \\
\text { (CI 95\%) }\end{array}$} & \multirow{3}{*}{$\mathbf{p}$} \\
\hline & & \multicolumn{2}{|c|}{ Không đúng } & \multicolumn{2}{|c|}{ Đúng } & & \\
\hline & & $\mathbf{n}$ & $\%$ & $\mathbf{n}$ & $\%$ & & \\
\hline \multirow{2}{*}{$\begin{array}{c}\text { Thâm niên công } \\
\text { tác }\end{array}$} & $<5$ năm & 20 & 13,9 & 124 & 86,1 & \multirow{2}{*}{$\begin{array}{c}1,7 \\
(0,9-3,2)\end{array}$} & \multirow{2}{*}{0,07} \\
\hline & > 5 năm & 24 & 8,7 & 252 & 91,3 & & \\
\hline
\end{tabular}

Không có mối liên quan có ý nghĩa thống kê giữa thâm niên công tác với thực hành phòng bệnh VGBNN với $p=0,07$. Nhóm ĐD có thâm niên công tác $<5$ năm thì thực hành về phòng bệnh VGB không đúnggấp 1,7 lần so với nhóm ĐD có thâm niên công tác >5 năm.

Bảng 3. 8. Môi liên quan giữa trình độ chuyên môn và thực hành phòng bệnh VGBNN $(N=420)$

\begin{tabular}{|c|c|c|c|c|c|c|c|}
\hline \multirow{3}{*}{\multicolumn{2}{|c|}{ Biến độc lập }} & \multicolumn{4}{|c|}{ Thức hành phòng bênh VGBNN } & \multirow{3}{*}{$\begin{array}{c}\text { OR } \\
(C I \\
95 \%)\end{array}$} & \multirow{3}{*}{$\mathbf{p}$} \\
\hline & & \multicolumn{2}{|c|}{ Không đúng } & \multicolumn{2}{|c|}{ Đúng } & & \\
\hline & & $\mathbf{n}$ & $\%$ & $\mathbf{n}$ & $\%$ & & \\
\hline \multirow{2}{*}{$\begin{array}{c}\text { Trình độ } \\
\text { chuyên môn }\end{array}$} & Đại học, Cao đằng & 18 & 12,7 & 124 & 87,3 & \multirow{2}{*}{$\begin{array}{c}1,4 \\
(0,7-2,6)\end{array}$} & \multirow[t]{2}{*}{0,18} \\
\hline & Trung hoc & 26 & 9,4 & 252 & 90,6 & & \\
\hline
\end{tabular}

Không tìm thấy mối liên quan có ý nghĩa thống kê giữatrình độ chuyên môn và thực hành phòng bệnh VGBNNvới $\mathrm{p}=0,18$. Nhóm $\mathrm{DD}$ có trình độ đại học - cao đẳng có thực hành phòng bệnh VGB không đúng gấp1,4 lần so với nhómĐD có trình độ trung học.

Bảng 3.9. Môi liên quan giữa kiến thức với thức hành phòng bệnh VGBNN $(N=420)$

\begin{tabular}{|c|c|c|c|c|c|c|}
\hline \multirow{3}{*}{ Kiến thức } & \multicolumn{4}{|c|}{ Thực hành phòng bệnh VGBNN } & \multirow{3}{*}{$\begin{array}{c}\text { OR } \\
\text { (CI 95\%) }\end{array}$} & \multirow{3}{*}{$\mathbf{p}$} \\
\hline & \multicolumn{2}{|c|}{ Không đúng } & \multicolumn{2}{|c|}{ Đúng } & & \\
\hline & $\mathbf{n}$ & $\%$ & $\mathbf{n}$ & $\%$ & & \\
\hline \multicolumn{7}{|c|}{ 1. Kiến thức về bệnh VGB $(N=420)$} \\
\hline Không đạt & 29 & 14,6 & 170 & 85,4 & \multirow{2}{*}{$\begin{array}{c}2,3 \\
(1,2-4,5)\end{array}$} & \multirow{2}{*}{0,007} \\
\hline Đạt & 15 & 6,8 & 206 & 93,2 & & \\
\hline \multicolumn{7}{|c|}{ 2. Kiến thức về phòng bệnh VGBNN $(N=420)$} \\
\hline Không đạt & 27 & 20,9 & 102 & 79,1 & \multirow{2}{*}{$\begin{array}{c}4,3 \\
(2,2-8,1)\end{array}$} & \multirow{2}{*}{$<0,0001$} \\
\hline Đạt & 17 & 5,8 & 274 & 94,2 & & \\
\hline \multicolumn{7}{|c|}{ 3. Kiến thức về xử trí sau phơi nhiềm $(N=420)$} \\
\hline Không đạt & 13 & 8,1 & 148 & 91,9 & \multirow{2}{*}{$\begin{array}{c}0,6 \\
(0,3-1,3)\end{array}$} & \multirow{2}{*}{0,1} \\
\hline Đạt & 31 & 12,0 & 228 & 88,0 & & \\
\hline
\end{tabular}

Bảng 3.9 cho thấy có mối liên quancó ý nghĩa thống kê giữa kiến thức về bệnh VGBNN với thực hành phòng bệnh VGBNN với $p=0,007$. Nhóm có kiến thức về bệnh VGBNN không đạt thì thực hành phòng bệnh VGBNN không đúng gấp 2,3 lần so với nhóm có kiến thức đat.

Có sự khác biệt giữa kiến thức về phòng bệnh VGBNN với thực hành phòng bệnh VGBNN. Nhóm có kiến thức không đạt thì thực hành phòng bệnh VGBNN không đúng gấp 4,3 lân so với nhóm kiến thức đạt, sự khác biệt này có ý nghĩa thống kêvới $p<0,0001$.

Kết quả nghiên cứu cho thấy không có mối liên quan có ý nghĩa thống kê giữa kiến thức về xử trí sau phơi nhiễm với thực hành phòng bệnh VGBNN với $p=0,1$.

Tuy nhiên, việc phản ánh phương tiện BHLĐ không đủ sử dụng do nhân viên khoa sử dụng không đúng cách. Năm 2017, Bộ Y tế có ban hành Quyết định 3916 hướng dẫn thực hành vệ sinh tay trong các cơ sở khám bệnh, chữa bệnh: Không phải lúc nào NVYT cũng mang găng, khẩu trang để thực hiện các thủ thuật.

"Hiện tại BV cung cấp bảo hộ lao động cho NVYT về số lượng và chất lượng đây đủ. Qua khảo sát thực tế thì các khoa thiếu sử dụng là do sử dụng khồng đúng mục đích khi thực hiện một số kỹ thuật thì không cần phải sử dụng găng hay khẩu trang" (PVS2-PĐD)

"Việc trang bi bảo hộ lao động cho NVYT của bệnh viện theo tôi là tốt. Tuy nhiên người sử dụng bảo hộ thì không biết sử dụng đúng mục đích để tiết kiệm và hiệu quả" (PVS3-KSNK).

Kết quả nghiên cưư định tính không thây có 
ảnh hưởng của việc trang bị bảo hộ lao động tới thực hành phòng bệnh viêm gan $B$ nghề nghiệp của điều dưỡng.

Kiến thức chuyên đề về các bệnh nghề nghiệp chưa được bệnh viện triển khai đào tạo, mà chỉ tập huấn kiến thức phòng ngừa chung.

"Mỗi năm, chúng tôi đều được bệnh viện cho đi dự các lớp tập huấn chuyên môn, như kiểm soát nhiễm khuẩn, nhưng chỉ phòng ngừa chung thôi, những kiến thức cập nhật kiến thức về viêm HIV hay VGB thì không có" (TLN).

"Để phòng bệnh riêng cho VGB thì không có mà nằm chung trong chương trình phòng ngừa lây nhiễm chung. Tập huấn kết hợp vừa HIV, VGB, các đường lây truyền khác như đường hô hấp thì lồng ghép vô" (PVS1-BLĐ).

Theo kinh nghiệm của bản thân, tôi thấy $Đ D$ nào có kiến thức tốt thì thực hành tốt hơn (TLN).

Kết quả nghiên cứu định tính cho thấy việc đào tạo, tập huấn không chuyên sâu ảnh hưởng đến khả năng xử lý của điêu dưỡng khi phơi nhiễm với vật sắc nhọn và thực hành phòng chống bệnh viêm gan $B$.

Nhân lực để kiểm tra, giám sát hoạt động chuyên môn vẫn còn thiếu, chủ yếu là kết hợp với khoa. Hoạt động kiểm tra, giám sát chủ yểu mang tính nhắc nhở, chưa thật sự răn đe.

"Điều dưỡng trưởng khoa tôi hàng ngày kiểm tra tất cả các buồng bệnh, nhắc nhở các anh chị phụ trách phòng, nhắc nhở tại chổ hoặc báo lên giao ban khoa hàng ngày" (TLN)

"Do nhân lực khoa KSNK hạn chế nên kiểm tra cũng không được thường xuyên. Giám sát trên tinh thần nhắc nhở cho nhân viên tuân thủ" (PVS3-KSNK).

"Điêu dưỡng trưởng chủ yếu nhắc thôi, trường hợp ảnh hưởng đến sức khỏe người bệnh mới được báo cáo lên cấp trên"(TLN).

"Lịch kiểm tra là định kỳ, nên một số khoa có sự chuẩn bị trước. Nhiều khi tôi xuống kiểm tra việc phân loại rác khoa thực hiện có đúng không thì lại không thấy rác, hỏi lại thì khoa dọn dẹp hết rồi"(PVS-K.KSNK).

Kết quả nghiên cứu định tính cho thây công táckiểm tra, giám sát có ảnh hưởng đến thực hành phòng bệnh viêm gan $B$ nghề nghiệp của điều dưỡng.

\section{BÀN LUÂN}

Khi phân tích đơn biến, không tìm thấy mối liên quan giữa các yếu tố cá nhân của $\mathrm{DD}$ với thực hành phòng bệnh VGBNN có ý nghĩa thống kê $(p>0,05)$.

Nghiên cứu đã phân tích về mối liên quan giữa kiến thức hiểu biết về bệnh và phòng bệnh VGBNN của ĐD tham gia nghiên cứu với thực hành phòng bệnh VGBNN, kết quả cho thấy có sự khác biệt giữa kiến thức về bệnh VGBNN với thực hành phòng bệnh VGBNN. Nhóm có kiến thức không đạt thì thực hành phòng bệnh VGBNN không đúng gấp 2,3 lần so với nhóm kiến thức đạt. Sự khác biệt này có ý nghĩa thống kê $(p=0,007)$.Có sự khác biệt có ý nghĩa thống kê giữa kiến thức về phòng bệnh VGBNN với thực hành phòng bệnh VGBNN. Nhóm có kiến thức không đạt thì thực hành phòng bệnh VGBNN không đúng gấp 4,3 lần so với nhóm kiến thức đạt $(p=0,0001)$. Điều này hoàn toàn phù hợp cả trên lý thuyết và thực hành khi $Đ D$ có kiến thức về bệnh VGB, biết được mối nguy hiểm của bệnh, nắm vững cơ chế lây truyền, các biểu hiện của bệnh hoặc các bước xử trí khi bi TNNN thì tiếp xúc trực tiếp với NB lúc thực hiện nhiệm vụ, điều dưỡng sẽ dự phòng với các yểu tố nguy cơ và hạn chế phơi nhiễm với bệnh VGB tốt hơn so với những người chưa nắm vững kiến thức về bệnh. Kết quả nghiên cứu này tương tự như các nghiên cứu trước đây $(12,13,14)$

\section{KẾT LUÂNN}

Có mối liên quan giữa thực hành phòng bệnh và kiến thức về bệnh viêm gan $B$ nghề nghiệp.

Có mối liên quan giữa thực hành phòng bệnh và kiến thức phòng bệnh viêm gan $B$ nghề nghiệp.

Các yếu tố quản lý có ảnh hưởng tới thực hành phòng bệnh viêm gan $B$ nghề nghiệplà: Đào tạo, tập huấn và kiểm tra, giám sát.

Nghiên cứu khuyến nghị đối với bệnh viện xây dựng kế hoạch và tổ chức các lớp tập huấn cho tất cả điều dưỡng nhằm nâng cao nhận thức về bệnh viêm gan $B$ nghề nghiệp và dự phòng phơi nhiễm.

\section{TÀI LIỆ THAM KHẢO}

1. Viện Vê sinh dịch tễ (1995), Tình hình viêm gan vi rút trên toàn thế giới và ơ Việt Nam. Những đề nghị về chiến lược tiếm phòng vằc xin viêm gan $B$ tại Việt Nam, Báo cáo của Viện Vệ sinh dich tể

2. Bồ Y tế (2016), Quy định về bệnh nghề nghiệp đươợc hương bảo hiểm xã hội, Thông tư số 15/2016/TT-BYT ngày 15/5/2016"

3. Vũ Bằng (2015), Bênh viêm $\mathrm{g}$ an vi rút nghề nghiệp, website:// moh.gov.vn/ pcbenhnghenghiep/ pages/ tintuc.aspx? CateID = 9\&ItemID $=848$, truy cập ngày 18/01/2018"

4.WHO (2010), The best practices for injections and related procedures toolkit, March 2010, Geneva

5. Pruss Rapitil E Ustun A, Hutin Y (2003), Introduction and methods: asessing the envvironment burden of disease at national and local level, Geneva, WHO.

6. WHO (2010), The best practices for injections and 
related procedures toolkit, March 2010, Geneva
WHO (2003), Injection
7. Safety,
http:www.WHO.int/injection_safety/en".
WHO (2003), Injection
http:www.WHO.int/injection_safety/en".

8. Khúc Xuyên (1999), Điều tra cơ bản thực trạng sức khỏe ngưới lao động tiếp xúc với vi sinh vật nguy hiểm (vi rút viêm gan $B$ ), Đề tài Khoa học Công nghệ cấp Bộ, 1999"

9. Nguyển Quang Tâp và Pham Trung Kiên (2007), Xác định tỷ lệ nhiếm vỉ rút viêm gan $B$, HBsAg, Anti-HBS, HbeẢg của cán bố y tế tai mốt số bệnh viện Thành phố Hải Phòng, Tạp chí Y học Thực hành số 12/2007, tr. 32-35

\section{TÁC DỤNG ĐIỀU TRI ĐAU THẮT LƯNG DO THOÁI HÓA CộT SỐNG BẰNG XÔNG HƠI THUỐC KẾT HợP HOÀN CHİ THỐNG}

\section{TÓM TẮT}

Mục tiêu: đánh giá tác dụng giảm đau và cải thiện vận động cột sống bằng xông hơi thuốc kết hợp Hoàn chỉ thống trên bệnh nhân đau thắt lưng do thoái hóa cột sống thể hàn thấp. Đối tượng và phương pháp nghiên cứu: 40 bệnh nhân tuổi trên 30, được chẩn đoán đau thắt lưng do thoái hóa cột sống, phù hợp chứng Yêu thống thể hàn thấp theo $\mathrm{Y}$ học cổ truyền, không phân biệt giới tính, nghề nghiệp, tình nguyện tham gia nghiên cứu. Được điều trị bằng uống Hoàn chỉ thống kết hợp xông hởi thuốc cục bộ vùng cột sống thắt lưng trong 15 ngày, so sánh kết quả trước và sau điều trị. Kết quả: $92,5 \%$ đạt hiệu quả tốt và khá sau điều trị; điểm VAS giảm từ 6,33 (điểm) trước điều trị xuống còn 2,03 (điểm) sau điêu trị; chỉ số Schober tăng từ $2,25(\mathrm{~cm})$ trước điêu trị lên 3,67 (cm) sau điều trị; điểm ODI trung bình tăng từ 5,1 (điểm) trước điêuu trị lên 12,83 (điểm) sau điều trị, khác biệt có ý nghĩa thống kê. Kết luận: xông hởi thuốc kểt hợp Hoàn chỉ thống hiệu quả tốt trong điều trị đau thắt lưng do thoái hóa cột sống.

Tư khóa: Xông hơi thuốc, Hoàn chỉ thống, đau thắt lưng.

\section{SUMMARY \\ THE EFFECT ON TREATING LOW BACK PAIN DEGENERATIVE SPINE OF ON-SITE HERBAL SAUNA COMBINED WITH "HOAN CHI THONG"}

Objective: to evaluate the pain-relieved effect and improvement in lumbar spine's motor function of on-site herbal sauna combined with "Hoan Chi Thong" on patients. Subjects and methods: 40 volunteered patients aged over 30, diagnosed with low back pain degenerative spine, consistent with wind cold dampness by traditional medicine, regardless of gender or occupation, were participated in the study. Researchers combined using on-site herbal sauna with "Hoan Chi Thong" in 15 days, comparing the results before and after treatment. Result: indicated

*Viện Y học cổ truyền Quân đôi

Chịu trách nhiệm chính: Nguyển Vinh Quốc

Email: quocnguyenvinh@gmail.com

Ngày nhận bài: 16.3 .2021

Ngày phản biên khoa học: 12.5.2021

Ngày duyệt bài: 21.5.2021
Nguyễn Vinh Quốc*, Vũ Văn Thái*

by the $92.5 \%$ rate of good and effective results after the treatment; the VAS score reduced from 6.33 (before the treatment) to 2.03 after the study; the Schober index raised from $2.25 \mathrm{~cm}$ to $3.67 \mathrm{~cm}$ after the treatment; the ODI score raised from 5.1 to 12.83 after the treatment, difference is statistically significant. Conclusion: the treating method using on-site herbal sauna with "Hoan Chi Thong" show pleasing outcome during low back pain degenerative spine medication.

Keywords: On-site herbal sauna, Hoan chi thong, low back pain.

\section{I. ĐĂT VẤN ĐỀ}

Đau thắt lưng do thoái hóa cột sống (THCS) là bệnh lý phổ biến, thường gặp trên lâm sàng, có xu hướng tăng cao trong xã hội hiện đại [1], [2], [3]. Bệnh gặp ở mọi lứa tuổi, giới tính, tâng lớp xã hội và nghề nghiệp lao động với biểu hiện lâm sàng cơ bản là đau [1], [2], [3], [4]... Đau thắt lưng do THCS gây ảnh hưởng không tốt tới khả năng lao động, sinh hoạt của người bệnh hoặc để lại các di chứng nặng nề, tạo gánh nặng cho bản thân người bệnh, cho gia đình và xã hội nếu không được điêuu trị [1], [4]. Do vậy, lựa chọn phương án điều trị hiệu quả bệnh lý này với thời gian và chi phí hợp lý, duy trì ổn định chức năng cột sống, hạn chế tái phát là vấn đề cân thiết, có ý nghĩa về khoa học y học cũng như ý nghĩa sâu sắc về mặt xã hội.

Theo $Y$ học cổ truyền (YHCT), đau thắt lưng do THCS được mô tả thuộc phạm trù "chứng tý" với bệnh danh yêu thống...[1], [2], [3]. Có nhiêuu phương pháp điều trị bệnh lý này mang lại hiệu quả tốt trong đó có dùng thuốc kết hợp với các kỹ thuật điều trị không dùng thuốc [3], [5], [6]...

Hoàn chỉ thống là thuốc do Viện YHCT Quân đội sản xuất có tác dụng chống viêm giảm đau, đã được chứng minh hiệu quả điêu trị đối với một số bệnh lý xương khớp [6], [7]... Xông hơi thuốc YHCT là phương pháp kết hợp giữa tác dụng điều trị của bài thuốc YHCT và tác dụng của nhiệt hơi, thường được áp dụng để điêu trị các chứng đau xương khớp [5], [8]. Nghiên cứu 